\title{
EMLÉKÜLÉS A MAGYAR TUDOMÁNYOS AKADÉMIÁN CHERNEL ISTVÁN SZÜLETÉSÉNEK 150. ÉVFORDULÓJA ALKALMÁVAL
}

\author{
Faragó Sándor \\ Soproni Egyetem, Vadgazdálkodási és Gerinces Állattani Intézet \\ University of Sopron, Institute of Wildlife Management and Vertebrate Zoology \\ H-9400 Sopron, Bajcsy-Zs u. 4., Hungary
}

\begin{abstract}
FARAGÓ S. (2019): COMMEMORATION OF THE $150^{\mathrm{TH}}$ ANNIVERSARY OF ISTVÁN CHERNEL'S BIRTH AT THE HUNGARIAN ACADEMY OF SCIENCES IN BUDAPEST. Hungarian Small Game Bulletin 14: $209-212$. http://dx.doi.org/10.17243/mavk.2019.209

On 4th June 2015 the Department of Agricultural Sciences of the Hungarian Academy of Sciences together with the Ministry of Agriculture organized a remembrance session entitled „Profession Filled with Soul”, which commemorated the 150th anniversary of the birth of Chernelházi ISTVÁN CHERNEL, the second leader of the Centre of Hungarian Ornithology. During the session six scientific lectures were held, which were about all the regions of the wide-range activities of ISTVÁN CHERNEL. The lecturers were as follows: IMRE SÖPTEI, SÁNDOR FARAGÓ, TIBOR HADARICS, LAJOS BALOGH and JÓZSEF GYURÁCZ.
\end{abstract}

KULCSZAVAK: CHERnEl IsTVÁN, Magyar Tudományos Akadémia, emlékülés KEY WORDS: ISTVÁN CHERNEL, Hungarian Academy of Sciences, commemoration

2015. június 4-én a Magyar Tudományos Akadémia Agrártudományok Osztálya a Földművelési Minisztérium társrendezésében - az MTA Székház, Felolvasótermében - került megtartásra „Lélekkel teljesített hivatás” címmel az az emlékülés, amely Chernelházi CHERNEL ISTVÁNra, a Madártani Intézet második vezetőjére emlékezett születésének 150. évfordulója alkalmával.

Az ülés kezdeményezője az MTA Agrártudományok Osztálya Erdészeti Tudományos Bizottsága, illetve annak Vadgazdálkodási albizottsága (Elnök: FARAGÓ SÁNDOR) volt. Az ülést FARAGÓ SÁNDOR, a kezdeményező albizottság elnöke vezette.

Az ülés elején méltató köszöntőket mondott:

NÉMETH TAMÁs, az MTA rendes tagja, az Agrártudományok Osztálya, osztályelnök

L. SIMON LÁSZLÓ parlamenti államtitkár (Miniszterelnökség)

V. NÉMETH ZSOLT államtitkár (Földmüvelésügyi Minisztérium)

Az ülés során hat tudományos előadás hangzott el, amelyek felölelték CHERNEL ISTVÁN széleskörü tevékenységének valamennyi területét. Az előadók és az előadások sorrendben az alábbiak voltak:

SÖPTEI IMRE - Magyar Nemzeti Levéltár Vas megyei Levéltára, Kőszegi Fióklevéltára, Köszeg Chernel István munkásságának ,genetikai” elöképei

FARAGÓ SÁNDOR - Vadgazdálkodási és Gerinces Állattani Intézet, Nyugat-magyarországi Egyetem, Sopron

Chernel István - Egy korszakos madártudós a 19-20. század fordulóján

HADARICS TIBOR - Vadgazdálkodási és Gerinces Állattani Intézet, Nyugat-magyarországi Egyetem, Sopron

Modern gondolatok Chernel István müveiben 

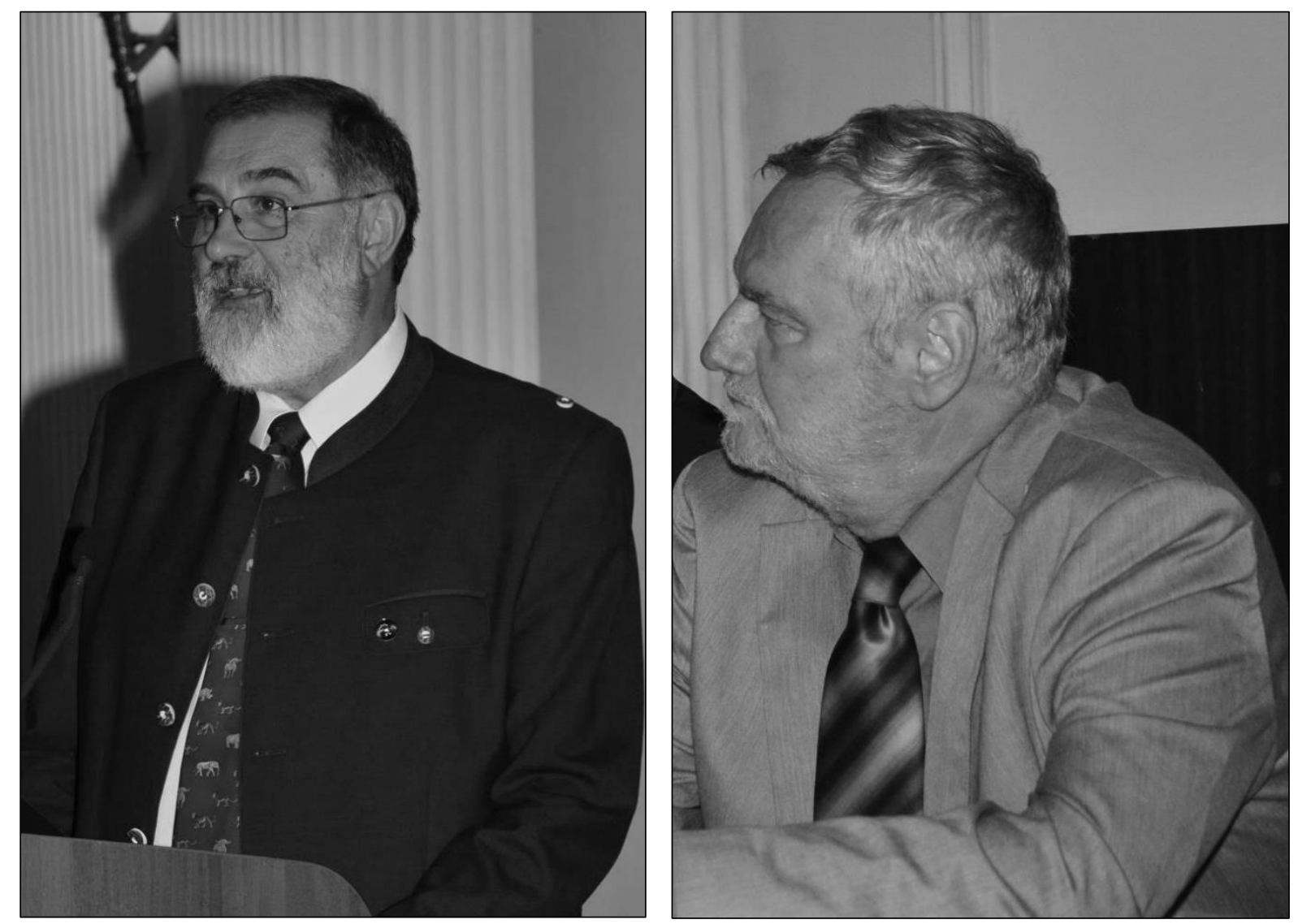

1. ábra: Köszöntő szavak - FARAGó SÁNDOR a konferencia elnöke és NÉMETH TAMÁS akadémikus, az MTA Agrártudományok Osztálya elnöke (Fotó: HADARICS T.)

Figure 1: Word of welcome-SÁNDOR FARAGÓ, president of the conference and TAMÁS NÉMETH member of HAS, section president of the Section of Agricultural Sciences of the Hungarian Academy of Sciences (Photo: T. HADARICS)

FARAGÓ SÁNDOR - Vadgazdálkodási és Gerinces Állattani Intézet, Nyugat-magyarországi Egyetem, Sopron

MAJTHÉNYI LÁSZLÓ - Vas megyei Közgyülés, Szombathely

$A$ vadászat nemes élvezete

BALOGH LAJOS - Savaria Megyei Hatókörü Városi Múzeum, Szombathely

Chernel István és a kert öröme

GYURÁCZ JÓZSEF - Biológia Intézet, Nyugat-magyarországi Egyetem, Szombathely \& Chernel István Madártani és Természetvédelmi Egyesület, Kőszeg

Chernel István madártani örökségének megörzése és továbbvitele a 21. században 

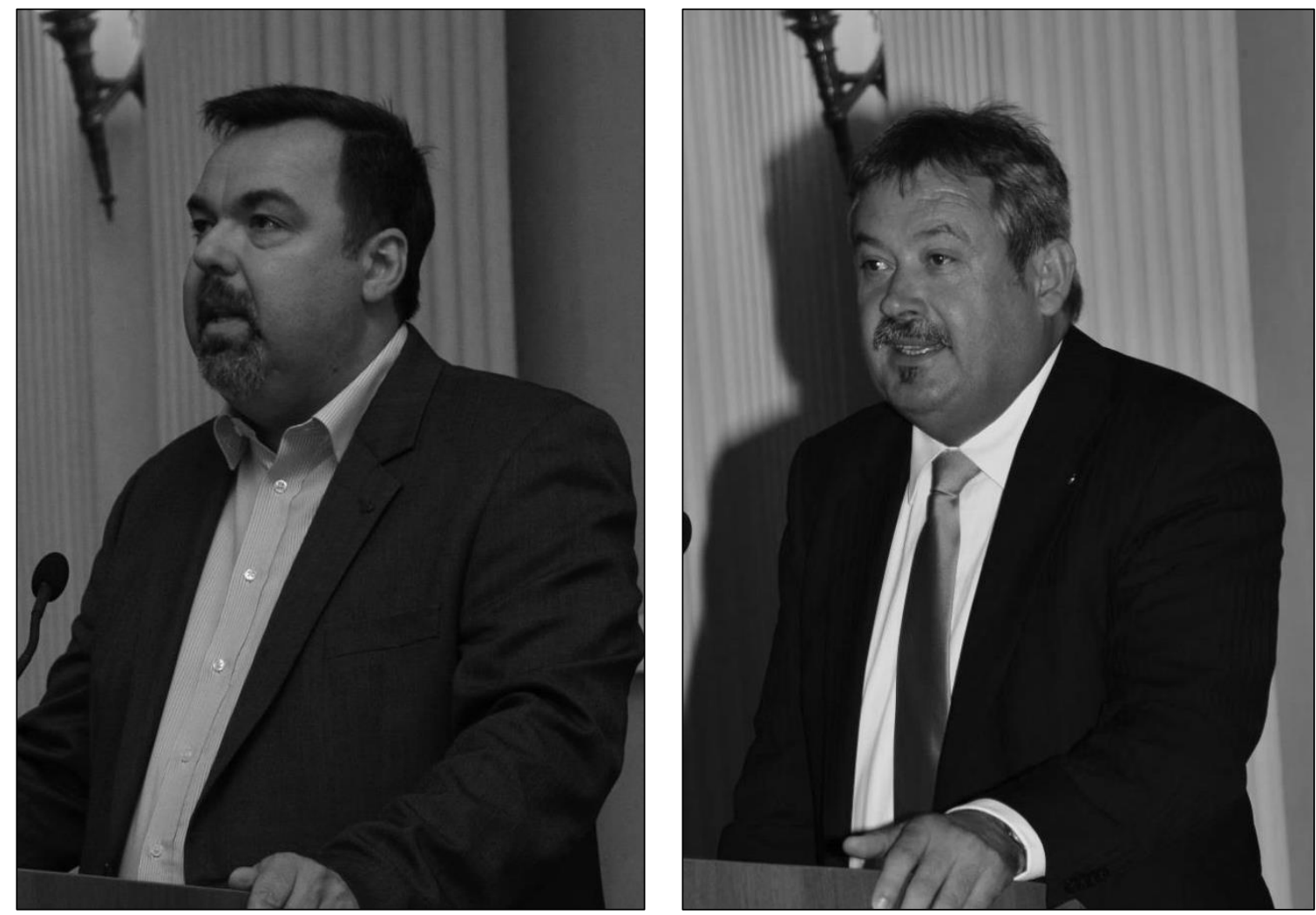

2. ábra: Köszöntő szavak - L. SIMON LÁSZLÓ államtitkár és V. NÉMETH ZSOLT helyettes-államtitkár (Fotó: HADARICS T.)

Figure 2: Word of welcome - LÁSZLÓ L. SIMON under-secretery of state and ZSOLT V. NÉMETH deputy under-secretery of state (Photo: T. HADARICS)
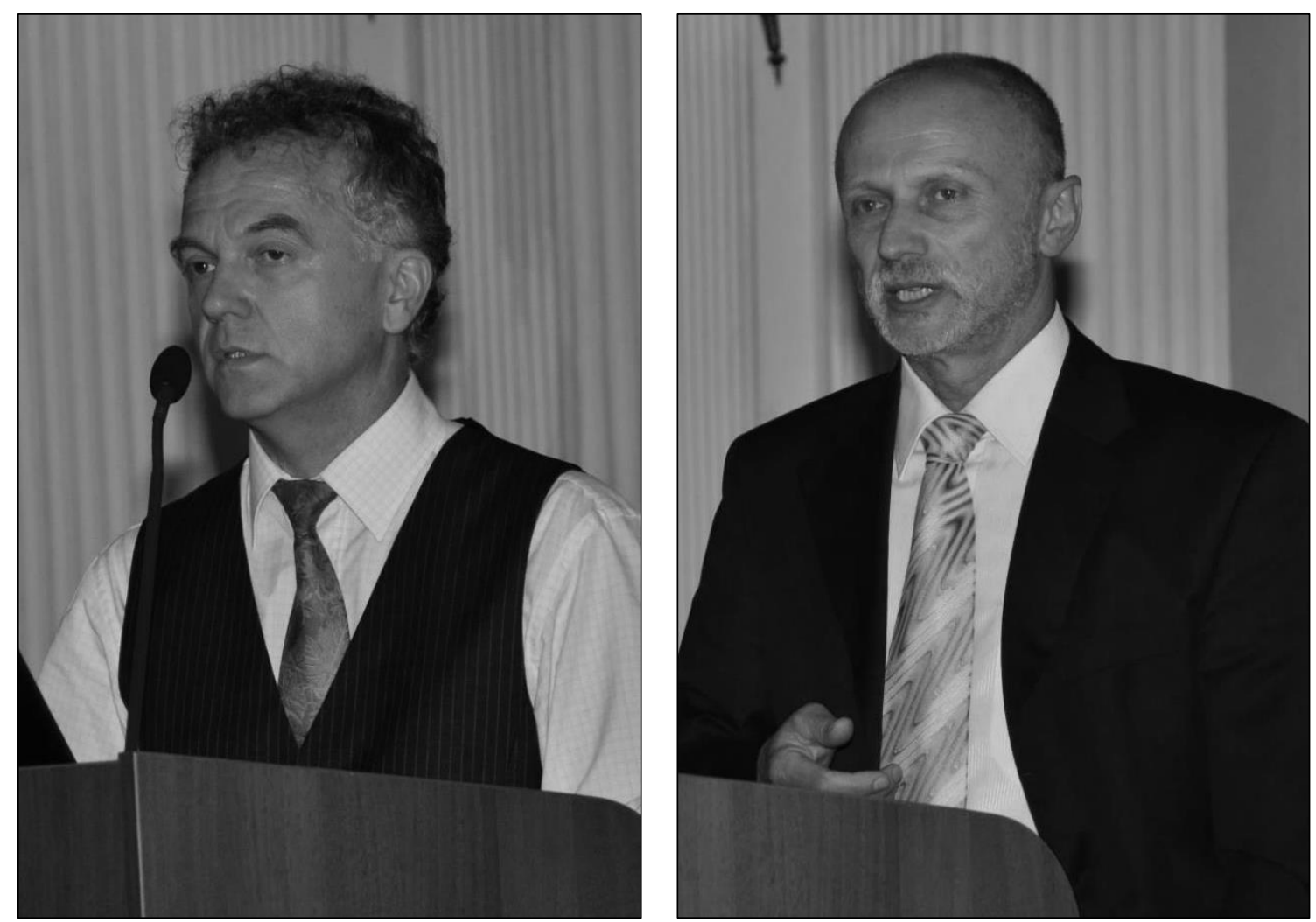

3. ábra: Előadók: BALOGH LAJOS és GYURÁCZ JózSEF (Fotó: HADARICS T.) Figure 3: Lecturers: LAJOS BALOGH and JÓZSEF GYURÁCZ (Photo: T. HADARICS) 


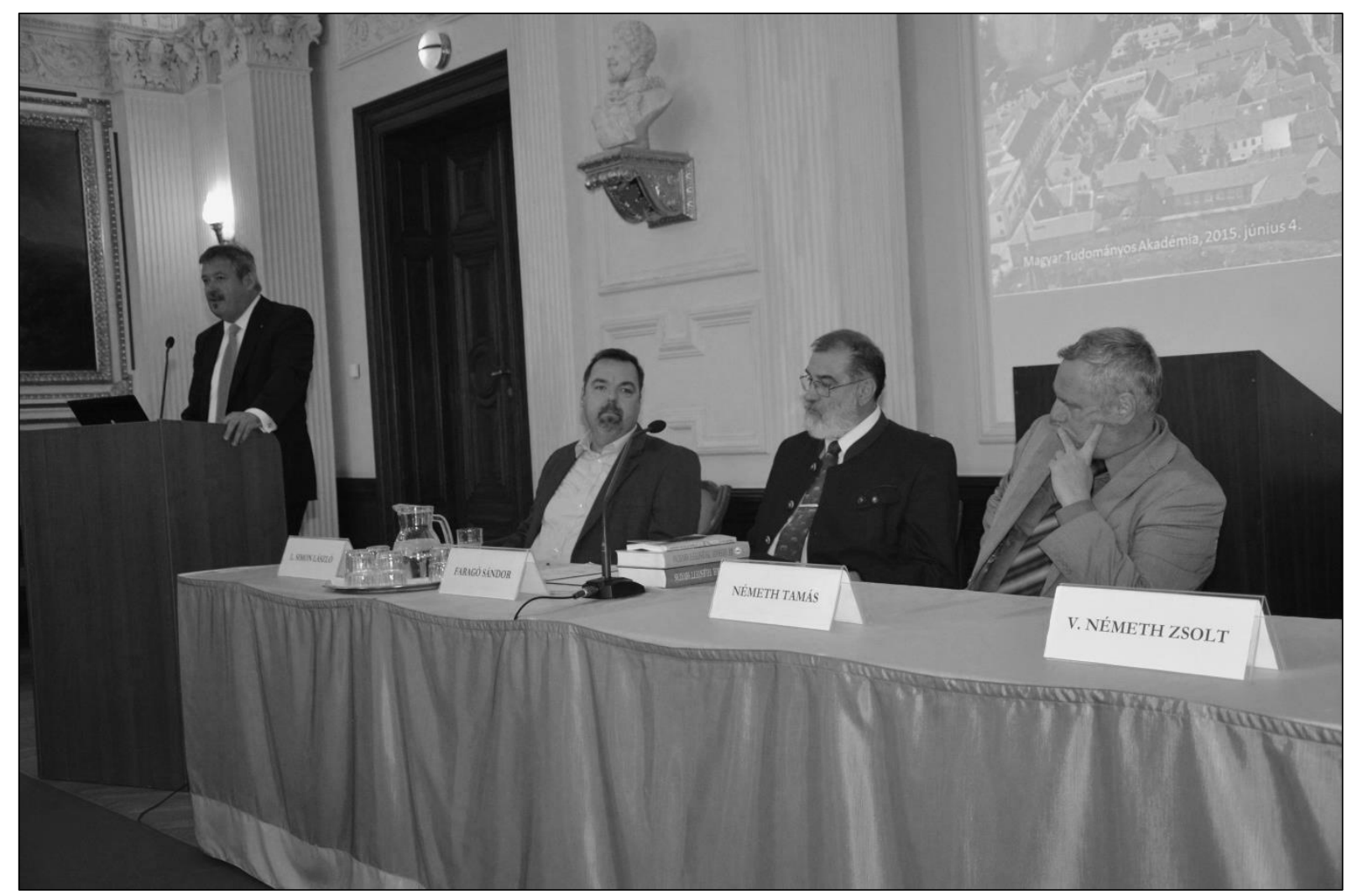

4. ábra: A konferencia elnöksége (Fotó: HADARICS T.)

Figure 4: The chair of the conference (Photo: T. Hadarics)

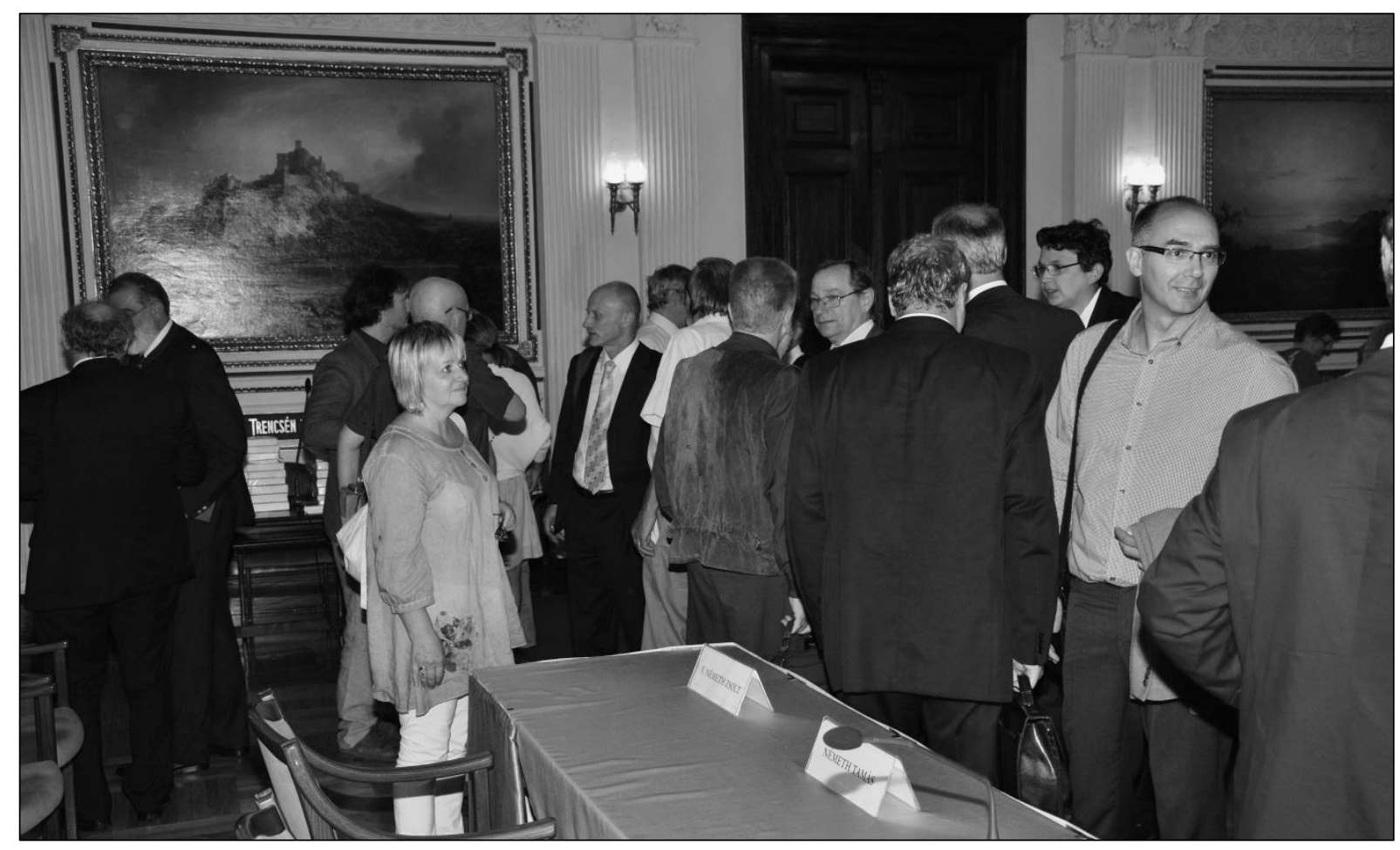

5. ábra. A konferencia résztvevőinek egy csoportja (FoTó: HADARICS T.)

Figure 5: A group of conference participants (Photo: T. HADARICS) 